Review

\title{
The Puzzle of Immunosuppressive Drugs
}

Anis Chaba ${ }^{1}$, Manon Dekeyser ${ }^{1,2}$, Julie Oniszczuk ${ }^{1,3}$, Antoine Durrbach ${ }^{1,2, *}$

1. Assistance Publique-Hôpitaux de Paris, Nephrology and Renal Transplantation Department, Groupe Hospitalier Henri-Mondor/Albert-Chenevier, Créteil, France; E-Mails: anis.chaba@hotmail.fr; manon.dekeyser@aphp.fr; antoine.durrbach@aphp.fr

2. UMRS 1186, Institut Gustave Roussy, Université Paris-Saclay, Villejuif, France

3. Université Paris-Est-Créteil, Département Hospitalo-Universitaire Virus-Immunité-Cancer, Institut Mondor de Recherche Biomédicale, Créteil, France

* Correspondence: Durrbach Antoine; E-Mail: antoine.durrbach@aphp.fr

Academic Editor: Maurizio Salvadori

Special Issue: Immunosuppression in Kidney Transplantation

OBM Transplantation

2021, volume 5, issue 1

doi:10.21926/obm.transplant.2101133
Received: August 30, 2020

Accepted: December 17, 2020

Published: January 11, 2021

\begin{abstract}
Kidney transplantation has become the preferred treatment option in end-stage chronic renal failure as it provides significant improvements over dialysis in terms of both quality and duration of life. Even after several randomized studies conducted in the last 20 years, the combination of $\mathrm{CNI}, \mathrm{MMF}$, and steroids continues to be considered the gold standard for kidney transplantation. However, novel molecules aimed at minimizing renal and cardiovascular toxicity, particularly with CNI sparing, are being identified. The present review assesses various such molecules available currently and briefly discusses the existing combination strategies and novel perspectives for the redesigning of protocols based on our novel therapeutic arsenal.
\end{abstract}

\section{Keywords}

Renal transplantation; calcineurin inhibitor; mTOR inhibitor; CTLA4-Ig; thymoglobulin

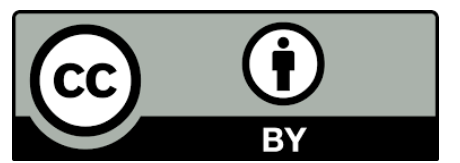

(C) 2021 by the author. This is an open access article distributed under the conditions of the Creative Commons by Attribution License, which permits unrestricted use, distribution, and reproduction in any medium or format, provided the original work is correctly cited. 


\section{Introduction}

In 2020, transplantation is undoubtedly considered the best treatment option in end-stage kidney disease as it offers a better quality of life and increased survival compared to dialysis [1, 2]. Various developments in the field of immunosuppression have led to considerable progress in terms of short-term graft survival, particularly due to the decreased frequency of acute rejection and its consequences. However, not much progress has occurred in terms of long-term graft survival, which presents an overall graft failure rate of $20 \%$ even after ten years since it was first introduced [3]. Calcineurin inhibitors (CNI) probably provide the best immune protection during the first year, although there are frequent reports describing chronic renal toxicity and adverse metabolic effects caused by CNI. Novel molecules aimed at minimizing treatment toxicity, particularly by reducing the recourse to CNIs, have been developed, although only a few of these have been proven to be suitable alternatives to CNIs as their benefits are frequently counterbalanced by the disappointing results in terms of rejection or adverse effects. In the present review, the various molecules currently available are assessed, and an overview of the existing combination strategies and novel perspectives in the redesigning of treatment protocols are provided based on our already extensive therapeutic arsenal.

\section{Available Molecules}

\subsection{The Alloimmune Response (Figure 1)}

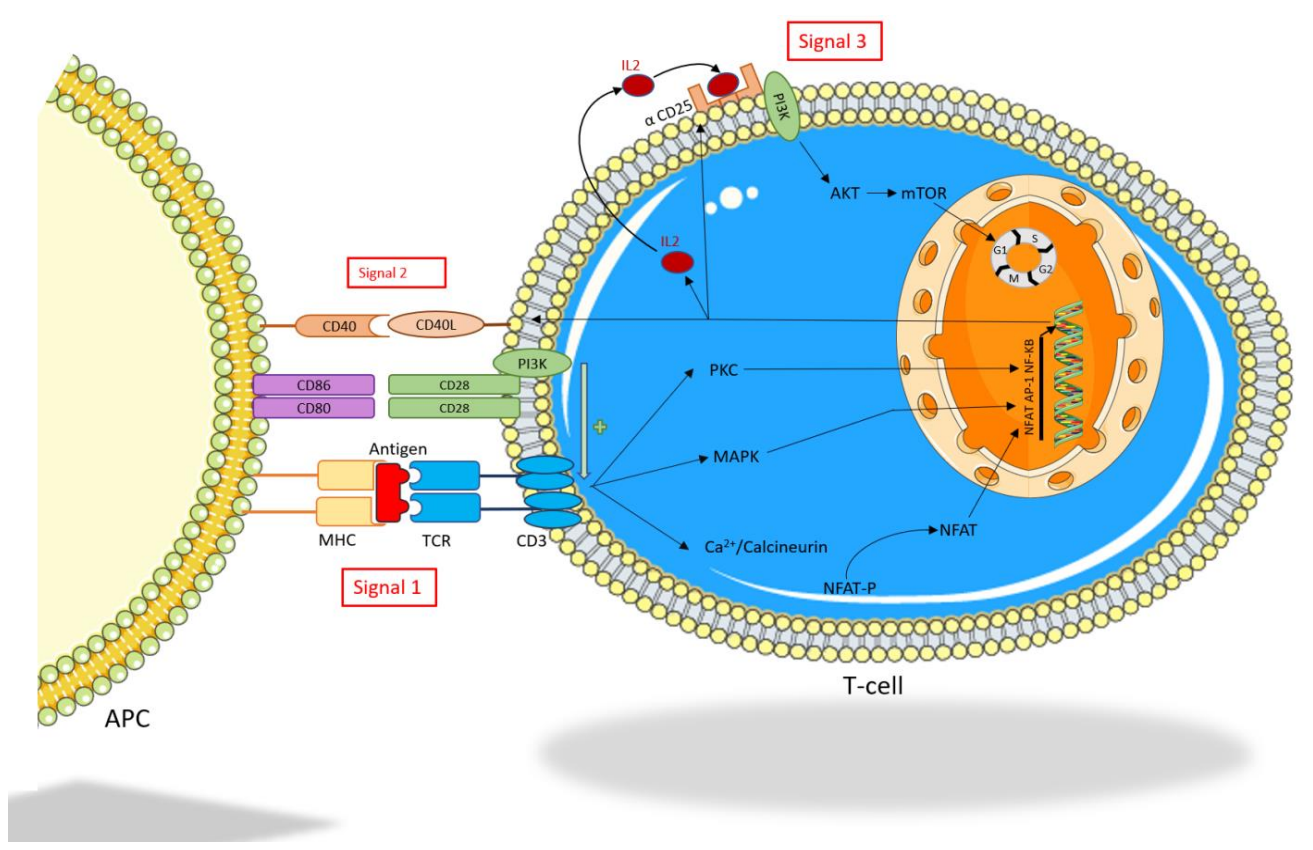

Figure 1 T-cell activation. APC: Antigen-presenting cell; MHC: Major histocompatibility complex; TCR: T-cell receptor; MAPK: Mitogen-activated protein kinase; PKC: Protein kinase C; PI3K: Phosphatidylinositol 3 kinase; NFAT: Nuclear factor of activated T cells; AP-1: Activator protein 1; NF-KB: Nuclear factor kappa B; IL: Interleukin; mTOR: Mammalian target of rapamycin. 
T cells are considered the chief orchestrators in the alloimmune response and are, therefore, the main target in anti-rejection therapy. The activation of $T$ cells requires three signals, the first of which results from the interaction of T cells with an antigen-presenting cell (APC) that presents an allopeptide to the T-cell receptor via type I or type II MHC.

The second costimulatory signal results from the interaction of CD80/CD86 located on the APC with the CD28 present on the T cell. These two signals activate the calcium/calcineurin, RAS MAP kinase, and NFKB pathways, leading to the following three important events: (i) the expression of CD40L, a key element in the stimulation signal; (ii) the production of various cytokines, including the interleukin 2 which is the cornerstone of T-cell proliferation, and (iii) the transcription of the alpha chain of the IL-2 receptor ( $\alpha$-CD25), which improves the affinity of IL2 toward its receptor. The third signal involves IL-2 binding via an autocrine/paracrine pathway, leading to the activation of the $\mathrm{Pi} 3 \mathrm{~K} / \mathrm{AKT} / \mathrm{mTOR}$ pathway, thereby triggering a lymphocyte-proliferation signal.

The different cytokines released by the T cells are also involved in the activation of other cells that participate in graft rejection. The inhibition of these three signals involved in the activation of T cells is, therefore, expected to favor long-term graft acceptance.

\subsection{Therapeutic Arsenal}

Various molecules with the capability of controlling the activation and proliferation of T cells have been developed. Some of these molecules eliminate $T$ cells to facilitate the restoration of a T-cell population with a different repertoire, while the other molecules aim to control the existing T cells by inhibiting their cytokine production.

\subsubsection{Polyclonal Antilymphocyte Sera}

Antilymphocyte sera are produced by the animals (rabbits or horses) immunized with lymphoid cells derived from the human thymus or a human cell lineage (such as Jurkat cells). These antibodies cause profound T-cell and B-cell depletion within a few hours of administration, followed by immune reconstitution shortly after the perfusion ends. However, total immune reconstitution occurs over months following the initial perfusion, with memory $T$ lymphocytes reappearing more rapidly compared to naive lymphocytes. This approach has been demonstrated to prevent acute rejection in highly sensitized patients more efficiently compared to an absence of induction or induction with anti-CD25 antibodies [4]. However, the lack of specificity and the higher levels of immunosuppression increase the risk of infection and neoplasia [5-7]. Furthermore, xenogeneic molecules could be associated with a risk of manifestations of the serum sickness disease, which occurs less frequently since the treatment duration was reduced from three to five days.

\subsubsection{Humanized Monoclonal Anti-CD52 Antibody}

Alemtuzumab is a humanized IgG1 monoclonal antibody directed against CD52, a glycoprotein present on circulating $T$ cells and $B$ cells, monocytes, macrophages, natural killer cells, and granulocytes. Alemtuzumab was initially used for treating chronic lymphocytic B-cell leukemia, and now, it is also used off-label as an induction agent in renal transplantation. Similar to polyclonal antilymphocyte sera, alemtuzumab also induces an immediate and profound depletion, followed by reconstitution with lymphocytes exhibiting a phenotype shift toward a higher proportion of memory 
T cells [8]. However, accumulating evidence suggests that this cell population may trigger alloimmunization $[9,10]$. The adverse effects of alemtuzumab include cytopenia and, in rare cases, autoimmunity (hemolytic anemia, thrombopenia, and hyperthyroidism), in addition to a higher incidence of infections or tumors. Alemtuzumab has the advantage over thymoglobulins in being a monoclonal agent with less variability between the batches, although it also has a narrower spectrum of effects as thymoglobulins act on several targets.

\subsubsection{Monoclonal Anti-CD25 Antibody (Anti-rlL2 Antibody)}

The activation of the IL-2 receptor leads to T-cell proliferation (Figure 1). Basiliximab is a chimeric blocking antibody that targets the $\alpha$-CD25 chain of the IL-2 receptor (rIL2) and is, therefore, used as an induction agent in transplantation. It presents a higher immunological risk as it does not deplete and induces less-marked immunosuppression. Anti-rlL2 antibodies have been demonstrated to be more efficient in preventing acute rejection in patients who are not highly sensitized [11-13]. However, several lines of evidence suggest that anti-rlL2 antibodies may impair the development of regulatory T cells, which require low-dose IL2 stimulation for their expansion [14-17]. However, no major specific adverse effects are reported for anti-rlL2 antibody treatment. In the large SYMPHONY trial [18], induction with an anti-rlL2 antibody (daclizumab) combined with low doses of cyclosporine $A$ and mycophenolate acid resulted in the same rate of acute rejection as was observed in the patients receiving a standard dose of cyclosporine A without rIL2 induction. Anti-rIL2 induction, therefore, appears to allow $\mathrm{CNI}$ exposure during the initial phase of transplantation.

\subsubsection{Corticosteroids}

Steroids exhibit immunosuppressive effects manifested by inhibiting the production of various vasoactive cytokines, such as IL-2 IL1, IL6, and TNF $\alpha$ via two main pathways- one is by binding to the corticosteroid receptor, which leads to the migration of the complex toward the nucleus, where it induces or represses gene expression, and the other is a direct action, in which they regulate the action of transcription factors, such as AP1 or NF- $\kappa B$, by stabilizing their cytosolic inhibitors. Despite several studies attempting to eliminate these drugs from the maintenance therapy to minimize their adverse cardiovascular, metabolic, bone, or skin effects, steroids continue to be a key induction agent in cancer treatment [19-22]. However, due to the minimal use of steroids in maintenance therapy, fewer studies are being conducted now with steroid withdrawal, highlighting the implication of these molecules in the complicated mechanisms involved in graft acceptance.

\subsubsection{Calcineurin Inhibitors (CNIs)}

CNIs are small molecules that interact with the cytosolic proteins referred to as immunophilins (FK-BPs or CyPs). These interactions cause the inhibition of calcineurin, a phosphatase implicated in the dephosphorylation of the transcription factor NFAT, which is a key player in the T-cell activation cascade. However, redundancy in this pathway has been observed, warranting the use of other molecules in combination with the CNIs for the induction of graft acceptance. Moreover, CNIs have a narrow therapeutic window and, therefore, require constant monitoring to improve their efficacy and reduce their toxicity. However, since their discovery in the 1980s, CNIs have been a key treatment element in solid organ transplantation, despite their toxicity, which is independent of 
their immunosuppressive properties and includes neurological, nephrological, and metabolic effects. The nephrotoxicity of CNIs is a major problem. CNIs cause direct reversible vasoconstriction that may lead to acute kidney injury. CNIs are also implicated in chronic lesions, such as arteriole hyalinosis and tubulointerstitial fibrosis, which appear to be related to the endothelial reticulum stress in various types of renal cells. CNIs may also cause thrombotic microangiopathy (TMA), probably via direct endothelial cell injury and/or dysfunction. They are also reported to be associated with a higher risk of developing hypertension, dyslipidemia, and de novo diabetes, all of which are associated with cardiovascular risk factors or mortality [23-26].

\subsubsection{Antimetabolites}

The duration between the 1960s and the 1980s was considered the golden era of azathioprine (AZA), which was demonstrated to extend canine allograft survival [27]. AZA suppresses the proliferation of the activated $T$ and $B$ cells and decreases the number of circulating monocytes by inhibiting the cell cycle of bone marrow promyelocytes. The antiproliferative effect of AZA is mediated by its metabolites, which act as chain terminators in DNA replication and also block the de novo purine base synthesis, a fundamental process in lymphocytes that lack the purine rescue pathway, by forming thioinosinic acid. The main complication of AZA treatment is the toxicity caused to the bone marrow and the liver.

Since the 2000s, the use of AZA decreased considerably, and the molecule was replaced by mycophenolate mofetil (MMF), which is a reversible inhibitor of inosine monophosphate dehydrogenase (IMDPH) isoform 2, an enzyme required for the de novo synthesis of purine bases. At the end of the $20^{\text {th }}$ century, MMF contributed greatly to the improvements in kidney survival. Nevertheless, the digestive and hematological toxicities caused by MMF represent a major barrier to its extensive application. Moreover, MMF also increases the risk of infection, particularly for viral diseases, despite being demonstrated to exhibit antiviral properties in vitro [28]. In addition, its pharmacodynamics is complex as its metabolism is regulated by various transporters, and individual drug exposure cannot be easily evaluated and requires the calculation of the area under the curve $(A \cup C)$ or mini AUC, which are difficult to reproduce during patient follow-up in real life.

\subsubsection{Mammalian Target of Rapamycin Inhibitors (mTOR Inhibitors)}

Sirolimus and everolimus block the proliferation signal by inhibiting the mTOR kinase. These drugs were originally developed to replace the CNIs as the cornerstone of immunosuppression. However, their generalized use is limited due to their adverse effects and the higher incidence of acute rejection reported in pivotal studies. For instance, in the SYMPHONY study, the rate of acute rejection in the patients treated with rapamycin plus MMF and induction with an anti-rlL2 antibody was $60 \%$ higher than that in the patients treated with low doses of cyclosporine combined with the same associated immunosuppressive therapies, and twice that in the patients treated with low doses of tacrolimus. A recent retrospective analysis suggested that the patients treated with mTOR inhibitors have a higher risk of developing de novo donor-specific antibody production. In addition, the mTOR inhibitors may cause renal lesion via various mechanisms, including proteinuria, as evidenced by their effects on the Pi3K/AKT/mTOR pathway in podocytes during renal injury [29], and microangiopathy, possibly due to a decrease in the glomerular secretion of VEGF [30]. Furthermore, their use in combination with full-dose CNIs results in increased renal toxicity. 
Moreover, sirolimus may interfere with recovery from acute tubular necrosis [31]. However, several studies have reported these drugs to be effective in reducing tumor development or preventing the recurrence of skin cancer in renal transplant patients, while the meta-analyses revealed that mTOR inhibitors are associated with a lower risk of viral infection in the renal transplant patients [32-34].

\subsubsection{Belatacept (BCT)}

Belatacept is a fusion protein that binds to the CD80/CD86 present on the APCs, thereby inhibiting the costimulatory signal, leading to the activation and proliferation of naive T cells (Figure 2). The main advantage of BCT is that it does not exhibit nephrotoxicity. The phase III BENEFIT study $[35,36]$ reported significant improvements in GFR in the patients on belatacept, although with the disadvantage of higher rates of cellular rejection compared to those in the patients on CNIs. However, the frequency of de novo donor-specific antibody (DSA) production is reported to be lower in the patients treated with belatacept compared to those on CNI regimens, and this effect is correlated with the inhibition of B-cell maturation. These effects have also been confirmed for longterm usage in a seven-year-long follow-up study. In addition to improving the renal function, belatacept appears to improve both metabolic profile and graft survival [37]. Since belatacept is administered as an intravenous infusion, it is convenient to monitor adherence compared to the orally-administered agents, thereby decreasing the risk of occult nonadherence.

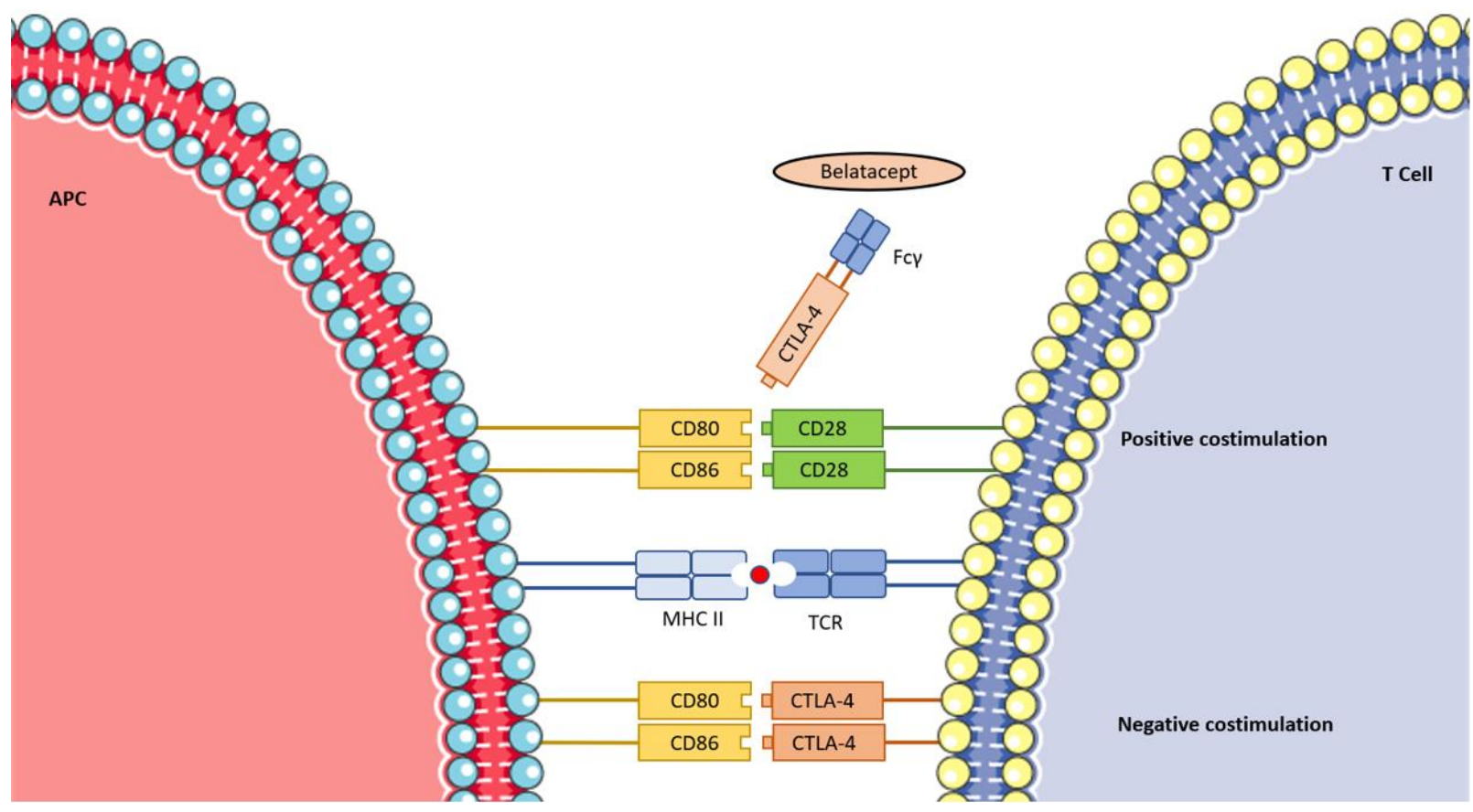

Figure 2 Costimulation blockade. MHC: Major histocompatibility complex; TCR: T-cell receptor; CTLA-4: Cytotoxic T lymphocyte-associated protein 4; APC: Antigen-presenting cell.

The risk of opportunistic infection (OPI) is not elucidated in the literature, although there are cases of disturbing viral reactivation and fungal infection reported quite frequently. In the initial phase of development, a higher incidence of post-transplantation lymphoproliferative disorders (PTLD) related to the primary infection with EBV was observed in the recipients. Recently, in a 
retrospective cohort, Bertrand et al. [38] reported an OPI frequency of approximately 12\%, essentially due to CMV reactivation and pneumocystis pneumonia. In the CMV-seronegative recipients of organs from seropositive donors, belatacept usage was associated with a higher incidence of CMV viremia, a higher rate of first-line treatment failure, a longer time for virus clearance, and cases of severe CMV retinitis [39, 40]. Certain cases of progressive multifocal leukoencephalopathy associated with the JC virus are reported. Our research group has also previously described a rapidly fatal case of PML associated with a refractory state of T-cell anergy, potentially due to belatacept therapy. This anergy state was characterized by a functional defect in the lymphocytes (affecting the cytokine secretion, proliferation, and cytotoxicity), which was associated with a strong expression of the inhibitory receptor PD-1. The treatment with a therapeutic anti-PD1 receptor antibody ex vivo failed to improve the T-cell function, which was consistent with the definition of lymphocyte anergy [41]. Although these data require confirmation in a larger case-control study, they nevertheless suggest that such events should be monitored carefully.

\section{Conventional Protocols}

\subsection{Induction}

High doses of corticosteroids considerably reduce the rate of rejection in the early stages of transplantation and, therefore, represent the cornerstone of induction treatment. They are used for reducing inflammation in the initial phase, which is followed by maintenance therapy. In several cases, this induction is combined with polyclonal antilymphocyte serum or basiliximab, leading to further lowering of the rates of rejection and graft loss [42].

In patients with low immunological risk, basiliximab is the most frequently used agent for limiting comorbidities or infectious diseases.

In most transplant centers, thymoglobulin (rATG) is routinely administered to immunized renal transplant recipients [43] as the preferred agent for T-cell depletion [44, 45], while the highly sensitized patients receive depleting agents to reduce both cellular and antibody-mediated rejection. In addition to the greater risk of neoplasia and infection, higher cardiovascular mortality is reported in renal transplant recipients [46]. Ducloux et al. characterized the CD4 T-cell lymphopenia as a potential immunological marker of immunosuppression $[47,48]$ in renal transplantation, and then demonstrated it to be associated with atherosclerosis and cardiovascular death [49]. According to these findings, it appears reasonable to reserve this treatment, as far as possible, to patients with an extremely high immunological risk, and to prefer basiliximab for more general use, particularly because of the increasing evidence of its safety, even in the high-risk patients. Recently, Phanish et al. [50] reported the results for a retrospective study, in which an immunosuppression regimen comprising basiliximab induction, tacrolimus, MMF, and prednisolone combined with early steroid withdrawal was investigated in low-risk patients and with MMF withdrawal in high-risk patients. The authors reported low acute rejection rates in both the groups (15.1\% and $13.9 \%$, respectively) along with high rates of graft function. Although a randomized study is required to further confirm these observations, the results are nonetheless highly promising.

Rituximab was recently evaluated as an induction therapy agent in solid organ transplantation. This monoclonal antibody acts against CD20 and induces rapid and profound depletion of $B$ 
lymphocytes. Rituximab has received approval for use in the treatment of lymphoma and leukemia. It is also used off-label for induction in the cases of $A B O$-incompatible (ABOi) transplantation due to its profound effect on B cells, particularly in the B1 cells. Rituximab has completely replaced splenectomy, decreasing the anti-agglutinin titers and generating interesting results, as graft survival in ABOi kidney transplants is now similar to that in the allogeneic kidney transplantation under the standard criteria, despite the potential increase in the risk of acute humoral transplant rejection [51, 52]. Interestingly, the rate of acute cellular rejection is generally reported to be similar to that in transplantation from the donors meeting the standard criteria, although certain studies have reported lower rates as well [53].

Rituximab is proposed as a treatment for humoral acute rejection due to its action on the B cells, although the results obtained to date, albeit in inadequately powered trials, are not convincing, suggesting that rituximab may not be as effective against the memory B-cell compartment and plasma cells. However, rituximab does act on B-cell precursors and has, therefore, been proposed as an induction therapy agent for reducing the production of donor-specific antibodies. Van den Hoogen et al. conducted a double-blind randomized study in patients treated with a conventional regimen and demonstrated that induction with $375 \mathrm{mg} / \mathrm{m}^{2}$ rituximab was associated with a lower rate of acute cellular and humoral rejection compared to the same regimen without induction in the sensitized patients but not in non-sensitized patients, with no increase reported in the risk of infection [54]. Tyden et al. had previously reported a trend toward lower rates of acute rejection in the patients receiving induction with $375 \mathrm{mg} / \mathrm{m}^{2}$ rituximab in a randomized study. Interestingly, low doses of rituximab (100 or $200 \mathrm{mg} / \mathrm{m}^{2}$ ) resulted in low rates of DSA in calcineurin-based regimens, although with a lower incidence of acute cellular rejection in the matched cohorts of patients as well. These findings suggest that rituximab also plays an important role in connection to the antigenpresenting cells and that the pre-transplantation use of rituximab may reduce the initial immunization [54-57]. In a recent case-control study concerning 230 kidney transplants from living ABO-compatible donors, half of the patients were administered a low dose (100 $\mathrm{mg}$ ) of rituximab, and acute cellular rejection was observed in $11 \%$ of these patients, and de novo DSA was observed in $13.9 \%$ of these patients, versus $21.7 \%(p<0.041)$ and $26.9 \%(p<0.005)$, respectively, in the patients treated with the conventional regimen. Moreover, the use of low-dose rituximab for induction was associated with a lower rate of CMV infection, suggesting the safety of this strategy. Low-dose rituximab may, therefore, be beneficial in sensitized patients as well as in the patients not receiving the induction therapy. These results require further confirmation in larger prospective studies.

\subsection{Maintenance}

Most of the trials concerning the maintenance treatments focus on a few molecules (CNI, AZA, MMF, mTOR inhibitors, prednisone, and belatacept), used in different combinations, mostly in the form of tritherapy. This combination of different molecules allows the blocking of T-cell activation via different pathways simultaneously and decreasing the doses in each treatment, thereby limiting the toxicity of each molecule individually.

On the basis of several randomized controlled trials, the combination of CNIs, MMF, and steroids has been identified as the gold standard for reducing the rate of graft rejection at one year after the kidney transplantation. The main concerns regarding this treatment relate to the nephrotoxicity of 
CNIs. Combinations of the rIL2-blocking antibody with tacrolimus, MMF, and steroids are reported to be superior to the similar combinations, including cyclosporine $A$ in place of tacrolimus, as evidenced by the acute rejection rates of $12.3 \%$ vs. $24 \%$ at one year $(p<0.001)$ and the glomerular filtration rates of $65.4 \pm 27 \mathrm{~mL} / \mathrm{min}$ vs. $59.4 \pm 25.1 \mathrm{~mL} / \mathrm{min}(p<0.001)$ for tacrolimus-based vs. cyclosporine A-based regimens [18]

An alternative strategy based on the combination of mTOR inhibitor with MMF and a steroid is reported. In the SYMPHONY study, a fourth arm was added to this combination, and the patients were treated with daclizumab, sirolimus, mycophenolate acid, and steroids. In comparison to the groups receiving tacrolimus or cyclosporine $\mathrm{A}$ (see above), the rejection rate was significantly higher at one year (37.2\%), and the GFR was $56.7 \pm 26.9 \mathrm{~mL} / \mathrm{min}$. In the ORION study [58], the same combination of sirolimus with steroids was reported to present a significantly higher acute rejection rate compared to $\mathrm{MMF} /$ tacrolimus (31.3\% vs. $8.2 \%$ ). Moreover, a higher rate of acute rejection (15.2\%) was observed in the third group of patients who initially received sirolimus plus tacrolimus, with a gradual withdrawal of CNIs. Two-thirds of the patients included in the study population were withdrawn from the study as they presented a high rate of rejection, and consequently, these strategies involving mTOR inhibitors without $\mathrm{CNI}$ had to be abandoned. Furthermore, despite a small improvement in renal function reported by certain studies, a higher frequency of rejection and, more importantly, a higher risk of the de novo development of DSA was observed in the patients [18]. However, the patients treated with mTOR inhibitor-based regimens presented a lower rate of viral infections and CMV- and BKV-associated nephropathy. In addition, as the mTOR inhibitors are known to block the cell cycle in various cell types, they are used for the treatment of renal or lung cancer. The mTOR inhibitors are also reported to decrease the incidence of skin cancer recurrence, suggesting the additional potential benefits of preventing tumor lesions in transplant patients.

Belatacept was the first biotherapy to be used as a maintenance treatment in kidney transplantation. The lack of nephrotoxicity and a better metabolic profile compared to the other treatments present belatacept as an ideal treatment drug. Belatacept has been used in combination with MMF and steroids for the induction therapy based on anti-rlL2 antibodies. The use of belatacept was validated in 2011 by two studies, BENEFIT (for donors with standard criteria) and BENEFIT EXT (for donors with extended criteria), which compared the introduction of this molecule de novo, without CNIs, into a standard triple-therapy that included cyclosporine. Belatacept is demonstrated to improve long-term renal function compared to cyclosporine-based regimens. In the BENEFIT study, belatacept also increased the predicted mean half-life of the kidney grafts, although this regimen was associated with a high rate of PTLD, limiting the use of this molecule in the EBV-positive patients. In addition, higher rates of rejection and more severe rejection were observed, with no impact on graft function, in the patients treated with belatacept, although surprisingly, fewer of these patients developed de novo DSA. Moreover, a lower risk of new-onset diabetes after transplantation (NODAT) was observed. The potential of belatacept in decreasing the development of anti-HLA antibody, together with the improvement observed in renal function, have prompted the researchers to search for appropriate partner molecules for belatacept.

Therefore, despite providing improvements in the renal function or decreases in the incidence of infection, the novel regimens based on mTOR inhibitors or belatacept have, so far, failed to fulfill the hopes of the physicians and patients. All have been developed in head-to-head comparisons, and it is possible that other combinations might be more powerful in allogeneic transplantation. 


\section{Novel Perspectives}

\subsection{CNI Minimization via mTOR Inhibitors}

Despite the poor results obtained with the combination of cyclosporine A and mTOR inhibitors in the initial study conducted in 1996, in which rapid development of renal fibrosis was observed, the low rate of acute rejection was encouraging as it suggested the synergetic action of these two molecules [59]. Improvements in the understanding of the therapeutic target of everolimus and the reports describing the beneficial effects of everolimus on tumor growth and viral infection prompted researchers to design novel protocols based on the combination of low doses of tacrolimus and everolimus. In the TRANSFORM study [60], the authors selected the lowest possible doses of $\mathrm{CNIs}$, and 2,000 patients with low immunological risk were included in this study comparing a combination of everolimus (trough concentration of 5 to $7 \mathrm{ng} / \mathrm{mL}$ ) and a CNI at a trough concentration half the usual level, with an arm in which MMF and CNI were administered to achieve the standard trough concentrations. No differences in renal function or rejection rate were observed at two years, although the viral infection rates were lowered by $60 \%$ in case of CMV infections and $45 \%$ in case of BKV-associated nephropathy [61]. These results have encouraged several research teams to review their protocols and propose similar CNI minimization strategies for the patients at low immunological risk.

\subsection{CNI Sparing via Immunotherapy}

The development of Belatacept regimens was hampered due to the acute rejection rates of $5 \%-$ $40 \%$ in the absence of CNIs, in contrast to the low rates of de novo DSA. Major efforts were put to eliminate the phenotype of the T cells resistant to belatacept. Several studies reported a correlation between the presence of high rates of CD4 or CD8 T cells and a memory or exhausted phenotype at the time of transplantation [62]. In primates, T cells lose CD28 during maturation, which potentially accounts for their CD28 independence and the lack of sensitivity to belatacept [63]. However, the CD28 T cells occur less frequently in humans, and the expression of CD28 is maintained on memory T cells. These cells appear to be Belatacept-resistant and are activated and continue to proliferate in the presence of belatacept, indicating that the combinations of mTOR inhibitors and belatacept should be used instead. Data from experiments on mice suggest that the concomitant blockade of costimulation and use of mTOR inhibitors promotes the apoptosis of activated alloreactive T cells and immunotolerance [64]. The other options are to deplete the memory compartment using the depleting agents in combination with belatacept or to use molecules capable of controlling memory $T$ cells in combination with belatacept for the initiation of the transplantation. Three different strategies have been envisaged. The first one involves induction therapy with $T$ cell-depleting antibodies, the second one involves an initial combination of belatacept with tacrolimus followed by rapid withdrawal of tacrolimus, and the third one uses a combination of belatacept with the mTOR inhibitors.

\subsubsection{Induction with Depleting Agents}

Pivotal studies were conducted with belatacept treatment developed with the use of basiliximab, an anti-rlL2 antibody for induction. Several studies have demonstrated that the number of memory 
cells on Day 0 correlates with the risk of developing acute rejection [65], which led to the development of an interesting strategy that involved the use of depleting antibodies for induction, along with belatacept, to eliminate the memory T cells. As reported by Ferguson [66] and the BEST study [67], the use of thymoglobulin or alemtuzumab in combination with Belatacept and MMF, along with rapid steroid withdrawal, is associated with a significantly higher rate of acute rejection in the belatacept arms compared to those in the tacrolimus arms. The BELACOR study conducted in 2019 prospectively assessed the potential benefits of Belatacept use for preventing antibodymediated rejection (AMBR) in patients with low MFI for preformed DSA; the induction therapy was based on thymoglobulins. Interestingly, while AMBR was not more frequent in the Belatacept group, the rate of T cell-mediated rejection (TCMR) was significantly higher in this group compared to the group receiving treatment with CNIs ( $25.4 \%$ vs. $5.64 \%$, respectively), with no difference in terms of graft survival or renal function [68]. Overall, these results suggest that depleting agents are ineffective in the long-term depletion of Belatacept-resistant T lymphocytes even in non-sensitized patients.

\subsubsection{Induction with $\mathrm{CNI}$ and Belatacept}

Most of the acute rejections occur in the first three months post-transplantation in the patients on Belatacept regimens. Therefore, for the first few months, the combination of a calcineurin inhibitor with belatacept, along with basiliximab for induction, was considered. Afterward, the CNI is gradually withdrawn to prevent acute rejection and avoid long-term toxicity [69]. Using this combination, the rate of acute rejection observed was lower than that observed in the BENEFIT regimen and higher than that in the comparator group. The curves of acute rejection-free survival revealed that acute rejection was delayed until the CNI was withdrawn or its dose was reduced, suggesting that CNIs may partly control Belatacept-resistant T cells but cannot eliminate them.

\subsubsection{Combination of Belatacept with mTOR Inhibitors}

The occurrence of acute rejection in patients receiving belatacept has led to the notion that Belatacept-resistant lymphocytes can proliferate and participate in graft rejection [62, 70, 71]. Fergusson et al. and Kirk et al. separately performed pilot studies evaluating the addition of an mTOR inhibitor to Belatacept treatment to control the rate of Belatacept-resistant T cells [59, 51]. The treatment also included induction with thymoglobulin. Interestingly, in a small group of patients, this strategy resulted in a low rate of acute rejection compared to the control group using a CNI ( $3 \%$ vs. $4 \%$, respectively), and despite the rapid withdrawal of steroids. Several patients discontinued the initial treatment because of the adverse effects, attributable, in most cases, to the use of mTOR inhibitors without steroids. Nevertheless, this pilot study was encouraging, and these results were again confirmed by two recent studies, in which treatment with belatacept plus mTOR inhibitors, along with the induction based on alemtuzumab or thymoglobulin, resulted in extremely low rates of acute rejection, suggesting a synergetic effect of these two molecules. However, these findings should be confirmed by larger, randomized studies. 


\subsection{Viral Infection in the Context of Kidney Transplantation and Immunosuppressive Treatment Management}

Viral infections are common causes of opportunistic infections after transplantation. The risk of a viral infection depends on various parameters, including the pathogen encountered, the immunosuppressive treatment used for preventing graft rejection, and other host factors, such as the cellular antiviral response. The treatment for viral infections generally includes antiviral agents and/or reduction of the immunosuppressive treatment to ensure an antiviral immune response without increasing the risk of rejection [73]. Since the antiviral response is mediated by CD8 T cells, an initial reduction or withdrawal of the antimetabolites and/or calcineurin inhibitors could be considered, although with an increased risk of graft rejection. Switching from the "standard" regimen to another protocol is also proposed as a means of preventing the viral infection. The mTOR pathway is involved in both lymphocyte expansion and viral replication. Recent data from studies in humans have suggested that the mTOR inhibitors exhibit antiviral effects in transplant patients, resulting in a lower risk of CMV, polyomavirus, and HHV8 infection, compared to the treatments combining calcineurin inhibitors, mycophenolate mofetil, and steroids [74]. The prospective ATHENA study, which evaluated a combination of everolimus, an mTOR inhibitor (mTORi), and a low dose of calcineurin inhibitor (tacrolimus or cyclosporine $A$ ) in comparison to a combination of tacrolimus and mycophenolic acid, reported lower rates of viral infections, but not of bacterial infections, at one year after transplantation [25.7\% for everolimus + tacrolimus, $11.6 \%$ for everolimus + cyclosporin A, $40.7 \%$ for tacrolimus + mycophenolic acid], while the rates for the CMV infection were $6.2 \%, 2.5 \%$, and $20.6 \%$, respectively, and those for BKvirus infection were $17.1 \%$, $9.1 \%$, and $22.5 \%$, respectively [75]. The lower rate of viral infection was not associated with a higher rate of acute rejection. However, the renal function was poorer in the group that received everolimus plus a calcineurin inhibitor.

Therefore, three different strategies may be proposed for non-immunized patients. The first is the use of mTORi + tacrolimus + steroid to decrease the rate of viral infection. The second is the use of a standard of care maintenance regimen with tacrolimus, mycophenolic acid, and steroids, and switching to an everolimus-based strategy in the cases of viral infection. In both these strategies, the physician should adapt the treatment according to the presence or absence of viral replication, regardless of whether a specific antiviral response is observed.

The third approach is an innovative one and is designed to increase the risk of viral infection without increasing the risk of rejection. This approach is based on the assessment of the ability of the cellular antiviral response to control viral reactivation [76]. Virus-specific T-cell monitoring is proposed as a means of optimizing the management of virus reactivation in transplant patients. Functional cellular immune responses are reported to be associated with the control of viral replication in the cases of infection with CMV or polyomavirus [77, 78]. Immunovirological monitoring could be used to provide personalized medical management to the patients through an individual assessment of the risk of viral reactivation. For instance, CMV-specific cellular immune monitoring has been demonstrated to predict CMV control after solid organ transplantation. An undetectable CMV-specific cellular immune response is associated with a higher risk of developing uncontrolled CMV reactivation. Therefore, CMV immune monitoring, in addition to clinical and DNA-based monitoring for CMV, could be included in the standard follow-up to improve CMV management [79]. Similarly, BKV-specific cellular immune responses are crucial for the control and 
clearance of BKV. BKV-specific T-cell dysfunction increases the risk of uncontrolled BKV infection, while the increases in the levels of BKV-specific CD8 $T$ cells are associated with a better prognosis in BKV-associated nephropathy. Nevertheless, BKV-specific cellular immune monitoring in the management of BKV infection should be explored because such assessments may guide the decreases in the intensity of immunosuppressive treatment as well as the increases after clearance [80].

\subsection{Transplantation in the Context of Cancer}

Numerous reports have highlighted the higher incidence of certain cancers in solid organ transplant patients, with non-melanoma skin cancers being the most frequently appearing ones. Since the mTOR inhibitor can inhibit the MTOR pathway involved in the cancer cell growth, the use of $m$ TOR inhibitors to reduce the recurrence of non-melanoma skin cancer appears to be attractive when combined with calcineurin inhibitors, compared to calcineurin inhibitor maintenance [81]. Similarly, in the CONVERT study, switching from a calcineurin inhibitor-based regimen to sirolimusbased immunosuppression was observed to be associated with a reduced incidence of malignancy in kidney transplant recipients [81]. Meta-analyses have confirmed this tendency mostly in terms of the occurrence of secondary non-melanoma skin cancer $[82,83]$. In these initial reports, mTOR inhibitors were used in place of CNI. However, recent observations of a higher risk of DSA occurrence in the patients treated with mTOR inhibitors along with mycophenolate acid and the interesting findings of the Transform and Athena study $[84,85]$ have suggested that the combination of an mTOR inhibitor with a low dose of CNI could be an effective strategy for the patients with the first appearance of non-melanoma skin cancer. The long-term outcomes of the Transform and Athena study would provide the essential information to decipher the effect of these approaches on the occurrence of skin cancer. The effect of the combination of an mTOR inhibitor with belatacept is currently unknown.

\subsection{Transplantation in the Context of Pregnancy}

Since transplantation was first performed, several female transplant recipients have retained the capability of becoming pregnant and having babies. In 2011, over 11,000 deliveries were recorded worldwide for female kidney recipients [86]. It is generally recommended to delay the pregnancy for at least a year after the transplantation due to the risk of graft failure [87]. The predictors of good maternal and fetal outcomes include young age of the mother, stable graft function with no recent episodes of graft rejection, a serum creatinine concentration of $<1.5 \mathrm{mg} / \mathrm{dL}$, a proteinuria level of $<500 \mathrm{mg}$ a day, and normal or well-controlled hypertension [86, 88, 89]. Immunosuppressive treatments, antihypertensive medication, and clinical parameters such as blood pressure may affect fetal development and pregnancy outcomes. For instance, angiotensin-converting enzyme and angiotensin 2 receptor inhibitor treatments should be terminated during pregnancy due to the risk of renal agenesis.

The data regarding the use of maintenance therapy during pregnancy or lactation are limited. Generally, calcineurin inhibitor treatments are maintained during pregnancy. Both cyclosporine and tacrolimus are associated with fetal growth retardation and prematurity, although not with malformations, and their withdrawal during lactation is generally not required. On the contrary, mycophenolic acid, being a teratogen, should be replaced with azathioprine at least a few weeks 
prior to attempting the conception. In the best-case scenario, the absence of proteinuria or the absence of an increase in proteinuria should be verified, together with the serum creatinine concentration and azathioprine tolerance (absence of leukopenia), prior to conception. Three months before any attempt at conception is a more comfortable time for treatment equilibration. In regard to the other molecules, limited evidence is available concerning the safety of the mammalian target of rapamycin inhibitors and belatacept, although a few pregnancies have been successful in the patients treated with Belatacept or Abatacept for autoimmune disease [90, 91]. mTOR is essential for placenta implantation as well as for the growth of most fetal organs, and its absence is embryo-lethal as mTORC1 and 2 play key roles in embryonic development and growth $[92,93]$. Finally, prednisone may be used safely in pregnant women [8]. The preferred regimen is, therefore, a combination of a calcineurin inhibitor with azathioprine and prednisolone. After delivery, azathioprine is frequently replaced with another molecule because of the stronger association of the former with skin carcinomas.

\section{Conclusions}

Kidney transplantation is becoming an increasingly complex procedure as its outcomes improve. Interestingly, novel combinations of the therapies that were initially developed independently have emerged as a potential alternative to the standard of care for reducing the CNI toxicity, decreasing the occurrence of infections or tumors, and limiting antibody-mediated rejection. In this context, the MTOR inhibitors and belatacept have re-emerged after a difficult departure and could serve as promising candidates in novel molecular combinations. Therefore, more trials are required to confirm the encouraging results presented by them and to respond to the diversity of patients undergoing kidney transplantation.

\section{Author Contributions}

All authors contributed to this work as follows: Writing: AC, JO, MD, AD; Editing: AC, JO, MD, AD.

\section{Competing Interests}

The authors have no competing interests to declare.

\section{References}

1. Wolfe RA, Ashby VB, Milford EL, Ojo AO, Ettenger RE, Agodoa LY, et al. Comparison of mortality in all patients on dialysis, patients on dialysis awaiting transplantation, and recipients of a first cadaveric transplant. N Engl J Med. 1999; 341: 1725-1730.

2. Tonelli M, Wiebe N, Knoll G, Bello A, Browne S, Jadhav D, et al. Systematic review: Kidney transplantation compared with dialysis in clinically relevant outcomes. Am J Transplant. 2011; 11: 2093-2109.

3. Hart A, Smith JM, Skeans MA, Gustafson SK, Wilk AR, Robinson A, et al. OPTN/SRTR 2016 annual data report: Kidney. Am J Transplant. 2018; 18: 18-113.

4. Mourad G, Morelon E, Noël C, Glotz D, Lebranchu Y. The role of Thymoglobulin induction in kidney transplantation: An update. Clin Transplant. 2012; 2: E450-E464. 
5. Morgan RD, O'Callaghan JM, Knight SR, Morris PJ. Alemtuzumab induction therapy in kidney transplantation: A systematic review and meta-analysis. Transplant J. 2012; 93: 1179-1188.

6. Cherikh WS, Kauffman HM, McBride MA, Maghirang J, Swinnen L, Hanto DW. Association of the type of induction immunosuppression with posttransplant lymphoproliferative disorder, graft survival, and patient survival after primary kidney transplantation1: Transplantation. 2003; 76: 1289-1293.

7. Lim WH, Turner RM, Chapman JR, Ma MK, Webster AC, Craig JC, et al. Acute rejection, T-celldepleting antibodies, and cancer after transplantation: Transplantation. 2014; 97: 817-825.

8. Bouvy AP, Klepper M, Betjes MG, Weimar W, Hesselink DA, Baan CC. Alemtuzumab as antirejection therapy: T cell repopulation and cytokine responsiveness. Transplant Direct. 2016; 2: e83.

9. Macedo C, Hadi K, Walters J, Elinoff B, Marrari M, Zeevi A, et al. Impact of induction therapy on circulating $T$ follicular helper cells and subsequent donor-specific antibody formation after kidney transplant. Kidney Int Rep. 2019; 4: 455-469.

10. Akbari M, Saha MN, Telfer S, Ullah S, Mok A, McAlister V, et al. Reconstitution of T-cell subsets following thymoglobulin-induced depletion in high immunologic risk and donation after cardiac death renal transplant recipients. Transplant Proc. 2019; 51: 1744-1753.

11. Ciancio G, Burke GW, Gaynor JJ, Carreno MR, Cirocco RE, Mathew JM, et al. A randomized trial of three renal transplant induction antibodies: Early comparison of tacrolimus, mycophenolate mofetil, and steroid dosing, and newer immune-monitoring 1. Transplantation. 2005; 80: 457465.

12. Lebranchu Y, Bridoux F, Büchler M, Meur YL, Etienne I, Toupance O, et al. Immunoprophylaxis with basiliximab compared with antithymocyte globulin in renal transplant patients receiving MMF-containing triple therapy. Am J Transplant. 2002; 2: 48-56.

13. Mourad G, Rostaing L, Legendre C, Garrigue V, Thervet E, Durand D. Sequential protocols using basiliximab versus anti-thymocyte globulins in renal-transplant patients receiving mycophenolate mofetil and steroids. Transplantation. 2004; 78: 584-590.

14. Safa K, Chandran S, Wojciechowski D. Pharmacologic targeting of regulatory $T$ cells for solid organ transplantation: Current and future prospects. Drugs. 2015; 75: 1843-1852.

15. Strom TB. 2006 Homer W. Smith lecture: Taming T cells. J Am Soc Nephrol. 2007; 18: 2824-2832.

16. Bouvy AP, Klepper M, Kho MM, Boer K, Betjes MG, Weimar W, et al. The impact of induction therapy on the homeostasis and function of regulatory $T$ cells in kidney transplant patients. Nephrol Dial Transplant. 2014; 29: 1587-1597.

17. Bluestone JA, Liu W, Yabu JM, Laszik ZG, Putnam A, Belingheri M, et al. The effect of costimulatory and interleukin 2 receptor blockade on regulatory $T$ cells in renal transplantation. Am J Transplant. 2008; 8: 2086-2096.

18. Ekberg H, Tedesco-Silva H, Demirbas A, Vítko Š, Nashan B, Gürkan A, et al. Reduced exposure to calcineurin inhibitors in renal transplantation. N Engl J Med. 2007; 357: 2562-2575.

19. Woodle ES, Peddi VR, Tomlanovich S, Mulgaonkar S, Kuo PC. A prospective, randomized, multicenter study evaluating early corticosteroid withdrawal with Thymoglobulin ${ }^{\circledR}$ in livingdonor kidney transplantation. Clin Transplant. 2010; 24: 73-83.

20. Vincenti F, Schena FP, Paraskevas S, Hauser IA, Walker RG, Grinyo J. A randomized, multicenter study of steroid avoidance, early steroid withdrawal or standard steroid therapy in kidney transplant recipients. Am J Transplant. 2008; 8: 307-316. 
21. Khwaja K, Asolati M, Harmon J, Melancon JK, Dunn T, Gillingham K, et al. Outcome at 3 years with a prednisone-free maintenance regimen: A single-center experience with 349 kidney transplant recipients. Am J Transplant. 2004; 4: 980-987.

22. Axelrod D, Leventhal JR, Gallon LG, Parker MA, Kaufman DB. Reduction of CMV disease with steroid-free immunosuppresssion in simultaneous pancreas-kidney transplant recipients. Am J Transplant. 2005; 5: 1423-1429.

23. Starzl TE, Fung J, Jordan M, Shapiro R, Tzakis A, McCauley J, et al. Kidney transplantation under FK 506. JAMA. 1990; 264: 63-67.

24. Myers BD, Ross J, Newton L, Luetscher J, Perlroth M. Cyclosporine-associated chronic nephropathy. N Engl J Med. 1984; 311: 699-705.

25. Rodrigo E, Fernández-Fresnedo G, Valero R, Ruiz JC, Piñera C, Palomar R, et al. New-onset diabetes after kidney transplantation: Risk factors: Table 1. J Am Soc Nephrol. 2006; 17: S291-S295.

26. Hošková L, Málek I, Kopkan L, Kautzner J. Pathophysiological mechanisms of calcineurin inhibitor-induced nephrotoxicity and arterial hypertension. Physiol Res. 2017; 66: 167-180.

27. Thomford NR, Shorter RG, Hallenbeck GA. Homotransplantation of the canine liver: Survival and histology with and without azathioprine. Arch Surg. 1965; 90: 527-538.

28. Sollinger HW. Mycophenolates in transplantation. Clin Transplant. 2004; 18: 485-492.

29. Canaud G, Bienaimé F, Viau A, Treins C, Baron W, Nguyen C, et al. AKT2 is essential to maintain podocyte viability and function during chronic kidney disease. Nat Med. 2013; 19: 1288-1296.

30. Estrada CC, Maldonado A, Mallipattu SK. Therapeutic inhibition of VEGF signaling and associated nephrotoxicities. J Am Soc Nephrol. 2019; 30: 187-200.

31. Bonegio R, Lieberthal W. Role of apoptosis in the pathogenesis of acute renal failure. Curr Opin Nephrol Hypertens. 2002; 11: 301-308.

32. Campbell SB, Walker R, Tai SS, Jiang Q, Russ GR. Randomized controlled trial of sirolimus for renal transplant recipients at high risk for nonmelanoma skin cancer. Am J Transplant. 2012; 12: 1146-1156.

33. Euvrard S, Morelon E, Rostaing L, Goffin E, Brocard A, Tromme I, et al. Sirolimus and secondary skin-cancer prevention in kidney transplantation. N Engl J Med. 2012; 367: 329-339.

34. Montero N, Quero M, Melilli E, Pérez-Sáez MJ, Redondo-Pachón D, Bestard O, et al. Mammalian target of rapamycin inhibitors combined with calcineurin inhibitors as initial immunosuppression in renal transplantation: A meta-analysis. Transplantation. 2019; 103: 2031-2056.

35. Vincenti F, Charpentier B, Vanrenterghem Y, Rostaing L, Bresnahan B, Darji P, et al. A phase III study of belatacept-based immunosuppression regimens versus cyclosporine in renal transplant recipients (BENEFIT Study). Am J Transplant. 2010; 10: 535-546.

36. Durrbach A, Pestana JM, Pearson T, Vincenti F, Garcia VD, Campistol J, et al. A phase III study of belatacept versus cyclosporine in kidney transplants from extended criteria donors (BENEFITEXT study). Am J Transplant. 2010; 10: 547-557.

37. Vincenti F, Rostaing L, Grinyo J, Rice K, Steinberg S, Gaite L, et al. Belatacept and long-term outcomes in kidney transplantation. N Engl J Med. 28 janv 2016; 374: 333-343.

38. Bertrand D, Chavarot N, Gatault P, Garrouste C, Bouvier N, Grall-Jezequel A, et al. Opportunistic infections after conversion to belatacept in kidney transplantation. Nephrol Dial Transplant. 2020; 35: 336-345. 
39. Karadkhele G, Hogan J, Magua W, Zhang W, Badell IR, Mehta A, et al. CMV high-risk status and posttransplant outcomes in kidney transplant recipients treated with belatacept. Am J Transplant. 2020; 21: 208-221.

40. Fan J, Gong D, Truong C, Miko B, Horowitz J, Chen RW. Cytomegalovirus retinitis with belatacept immunosuppression. Retin Cases Brief Rep. 2019.

41. Dekeyser M, de Goër de Herve M-G, Hendel-Chavez H, Labeyrie C, Adams D, Nasser GA, et al. Refractory T-cell anergy and rapidly fatal progressive multifocal leukoencephalopathy after prolonged CTLA4 therapy. Open Forum Infect Dis. 2017; 4: ofx100.

42. Szczech LA, Berlin JA, Feldman HI. The effect of antilymphocyte induction therapy on renal allograft survival: A meta-analysis of individual patient-level data. Ann Intern Med. 1998; 128: 817.

43. Thiyagarajan UM, Ponnuswamy A, Bagul A. Thymoglobulin and its use in renal transplantation: A review. Am J Nephrol. 2013; 37: 586-601.

44. Hardinger KL, Brennan DC, Klein CL. Selection of induction therapy in kidney transplantation. Transpl Int. 2013; 26: 662-672.

45. Gennarini A, Cravedi $P$, Marasà M, Perna A, Rota G, Bontempelli M, et al. Perioperative minimal induction therapy: A further step toward more effective immunosuppression in transplantation. J Transplant. 2012; 2012: 1-7.

46. Meier-Kriesche HU, Arndorfer JA, Kaplan B. Association of antibody induction with short- and long-term cause-specific mortality in renal transplant recipients. J Am Soc Nephrol. 2002; 13: 769-772.

47. Ducloux D, Carron PL, Rebibou JM, Aubin F, Fournier V, Bresson-Vautrin C, et al. CD4 lymphocytopenia as a risk factor for skin cancers in renal transplant recipients. Transplantation. 1998; 65: 1270-1272.

48. Ducloux D, Carron PL, Motte G, Ab A, Rebibou JM, Bresson-Vautrin C, et al. Lymphocyte subsets and assessment of cancer risk in renal transplant recipients. Transpl Int. 2002; 15: 393-396.

49. Ducloux D, Challier B, Saas P, Tiberghien P, Chalopin JM. CD4 cell lymphopenia and atherosclerosis in renal transplant recipients. J Am Soc Nephrol. 2003; 14: 767-772.

50. Phanish MK, Hull RP, Andrews PA, Popoola J, Kingdon EJ, MacPhee IA. Immunological risk stratification and tailored minimisation of immunosuppression in renal transplant recipients. BMC Nephrol. 2020; 21: 92.

51. Tydén G, Kumlien G, Genberg H, Sandberg J, Lundgren T, Fehrman I. ABO incompatible kidney transplantations without splenectomy, using antigen-specific immunoadsorption and rituximab. Am J Transplant. 2005; 5: 145-148.

52. Tanabe K, Ishida H, Shimizu T, Omoto K, Shirakawa H, Tokumoto T. Evaluation of two different preconditioning regimens for $\mathrm{ABO}$-incompatible living kidney donor transplantation. A comparison of splenectomy vs. rituximab-treated non-splenectomy preconditioning regimens. Contrib Nephrol. 2009; 162: 61-74.

53. Genberg H, Kumlien G, Wennberg L, Berg U, Tydén G. ABO-incompatible kidney transplantation using antigen-specific immunoadsorption and rituximab: A 3-year follow-up. Transplantation. 2008; 85: 1745-1754.

54. van den Hoogen MW, Kamburova EG, Baas MC, Steenbergen EJ, Florquin S, Koenen HJ, et al. Rituximab as induction therapy after renal transplantation: A randomized, double-blind, placebo-controlled study of efficacy and safety. Am J Transplant. 2015; 15: 407-416. 
55. Tomita Y, Iwadoh K, Ogawa Y, Miki K, Kato Y, Kai K, et al. Single fixed low-dose rituximab as induction therapy suppresses de novo donor-specific anti-HLA antibody production in ABO compatible living kidney transplant recipients. PloS One. 2019; 14: e0224203.

56. Tydén G, Genberg H, Tollemar J, Ekberg H, Persson NH, Tufveson G, et al. A randomized, doubleblind, placebo-controlled, study of single-dose rituximab as induction in renal transplantation. Transplantation. 2009; 87: 1325-1329.

57. Tydén G, Ekberg H, Tufveson G, Mjörnstedt L. A randomized, double-blind, placebo-controlled study of single dose rituximab as induction in renal transplantation: A 3-year follow-up. Transplantation. 2012; 94: e21-e22.

58. Flechner SM, Glyda M, Cockfield S, Grinyó J, Legendre C, Russ G, et al. The ORION study: Comparison of two sirolimus-based regimens versus tacrolimus and mycophenolate mofetil in renal allograft recipients. Am J Transplant. 2011; 11: 1633-1644.

59. Andoh TF, Lindsley J, Franceschini N, Bennett WM. Synergistic effects of cyclosporine and rapamycin in a chronic nephrotoxicity model 1. Transplantation. 1996; 62: 311-316.

60. Pascual J, Berger SP, Witzke O, Tedesco H, Mulgaonkar S, Qazi Y, et al. Everolimus with reduced calcineurin inhibitor exposure in renal transplantation. J Am Soc Nephrol. 2018; 29: 1979-1991.

61. Berger SP, Sommerer C, Witzke O, Tedesco H, Chadban S, Mulgaonkar S, et al. Two-year outcomes in de novo renal transplant recipients receiving everolimus-facilitated calcineurin inhibitor reduction regimen from the TRANSFORM study. Am J Transplant. 2019; 19: 3018-3034.

62. Espinosa JR, Samy KP, Kirk AD. Memory T cells in organ transplantation: Progress and challenges. Nat Rev Nephrol. 2016; 12: 339-347.

63. Mou D, Espinosa J, Lo DJ, Kirk AD. CD28 negative T cells: Is their loss our gain? Am J Transplant. 2014; 14: 2460-2466.

64. Li Y, Li XC, Zheng XX, Wells AD, Turka LA, Strom TB. Blocking both signal 1 and signal 2 of T-cell activation prevents apoptosis of alloreactive $T$ cells and induction of peripheral allograft tolerance. Nat Med. 1999; 5: 1298-1302.

65. Cortes-Cerisuelo M, Laurie SJ, Mathews DV, Winterberg PD, Larsen CP, Adams AB, et al. Increased pretransplant frequency of $\mathrm{CD} 28^{+} \mathrm{CD} 4^{+} \mathrm{T}_{\mathrm{EM}}$ predicts belatacept-resistant rejection in human renal transplant recipients. Am J Transplant. 2017; 17: 2350-2362.

66. Ferguson R, Grinyó J, Vincenti F, Kaufman DB, Woodle ES, Marder BA, et al. Immunosuppression with belatacept-based, corticosteroid-avoiding regimens in de novo kidney transplant recipients. Am J Transplant. 2011; 11: 66-76.

67. Woodle ES, Kaufman DB, Shields AR, Leone J, Matas A, Wiseman A, et al. Belatacept-based immunosuppression with simultaneous calcineurin inhibitor avoidance and early corticosteroid withdrawal: A prospective, randomized multicenter trial. Am J Transplant. 2020; 20: 1039-1055.

68. Leibler C, Matignon M, Moktefi A, Samson C, Zarour A, Malard S, et al. Belatacept in renal transplant recipient with mild immunologic risk factor: A pilot prospective study (BELACOR). Am J Transplant. 2019; 19: 894-906.

69. Wojciechowski D, Chandran S, Vincenti F. Early post-transplant conversion from tacrolimus to belatacept for prolonged delayed graft function improves renal function in kidney transplant recipients. Clin Transplant. 2017; 31: e12930.

70. Bestard O, Cassis L, Cruzado JM, Torras J, Franquesa M, Gil-Vernet S, et al. Costimulatory blockade with mTor inhibition abrogates effector T-cell responses allowing regulatory T-cell survival in renal transplantation. Transpl Int. 2011; 24: 451-460. 
71. Castro-Rojas CM, Godarova A, Shi T, Hummel SA, Shields A, Tremblay S, et al. mTOR inhibitor therapy diminishes circulating $\mathrm{CD} 8^{+} \mathrm{CD} 28^{-}$effector memory $\mathrm{T}$ cells and improves allograft inflammation in belatacept-refractory renal allograft rejection. Transplantation. 2020; 104: 1058-1069.

72. Kirk AD, Guasch A, Xu H, Cheeseman J, Mead SI, Ghali A, et al. Renal transplantation using belatacept without maintenance steroids or calcineurin inhibitors. Am J Transplant. 2014; 14: 1142-1151.

73. Kotton CN, Fishman JA. Viral infection in the renal transplant recipient. J Am Soc Nephrol. 2005; 16: 1758-1774.

74. Pascual J, Royuela A, Fernández AM, Herrero I, Delgado JF, Solé A, et al. Role of mTOR inhibitors for the control of viral infection in solid organ transplant recipients. Transpl Infect Dis. 2016; 18: 819-831.

75. Sommerer C, Suwelack B, Dragun D, Schenker P, Hauser IA, Witzke O, et al. An open-label, randomized trial indicates that everolimus with tacrolimus or cyclosporine is comparable to standard immunosuppression in de novo kidney transplant patients. Kidney Int. 2019; 96: 231-244.

76. Sester M, Leboeuf $C$, Schmidt T, Hirsch HH. The "ABC" of virus-specific t cell immunity in solid organ transplantation. Am J Transplant. 2016; 16: 1697-1706.

77. Dekeyser $M$, Ladrière $M$, Audonnet $S$, Frimat $L$, De Carvalho Bittencourt $M$. An early immediate early protein IE-1-specific T-cell polyfunctionality is associated with a better control of cytomegalovirus reactivation in kidney transplantation. Kidney Int Rep 2017; 2: 486-492.

78. Schaenman JM, Korin Y, Sidwell T, Kandarian F, Harre N, Gjertson D, et al. Increased frequency of BK virus-specific polyfunctional $\mathrm{CD}^{+} \mathrm{T}$ cells predict successful control of BK viremia after kidney transplantation. Transplantation. 2017; 101: 1479-1487.

79. Yong MK, Lewin SR, Manuel O. Immune monitoring for CMV in transplantation. Curr Infect Dis Rep. 2018; 20: 4.

80. Dekeyser M, François $H$, Beaudreuil S, Durrbach A. Polyomavirus-specific cellular immunity: From BK-virus-specific cellular immunity to BK-virus-associated nephropathy? Front Immunol. 2015; 6: 307.

81. Alberú J, Pascoe MD, Campistol JM, Schena FP, Rial MD, Polinsky M, et al. Lower malignancy rates in renal allograft recipients converted to sirolimus-based, calcineurin inhibitor-free immunotherapy: 24-month results from the CONVERT trial. Transplantation. 2011; 92: 303-310.

82. Knoll GA, Kokolo MB, Mallick R, Beck A, Buenaventura CD, Ducharme $R$, et al. Effect of sirolimus on malignancy and survival after kidney transplantation: Systematic review and meta-analysis of individual patient data. BMJ. 2014; 349: g6679.

83. Phan K, Moloney FJ, Hogarty DT, Lenane P, McColl D, Yazdabadi A. Mammalian target of rapamycin (mTOR) inhibitors and skin cancer risk in nonrenal solid organ transplant recipients: Systematic review and meta-analysis. Int J Dermatol. 2019.

84. Pascual J, Berger SP, Witzke O, Tedesco H, Mulgaonkar S, Qazi Y, et al. Everolimus with reduced calcineurin inhibitor exposure in renal transplantation. J Am Soc Nephrol. 2018; 29: 1979-1991.

85. Sommerer C, Suwelack B, Dragun D, Schenker P, Hauser IA, Witzke O, et al. An open-label, randomized trial indicates that everolimus with tacrolimus or cyclosporine is comparable to standard immunosuppression in de novo kidney transplant patients. Kidney Int. 2019; 96: 231-244. 
86. Deshpande NA, James NT, Kucirka LM, Boyarsky BJ, Garonzik-Wang JM, Montgomery RA, et al. Pregnancy outcomes in kidney transplant recipients: A systematic review and meta-analysis. Am J Transplant. 2011; 11: 2388-2404.

87. Kidney Disease: Improving Global Outcomes (KDIGO) Transplant Work Group. KDIGO clinical practice guideline for the care of kidney transplant recipients. Am J Transplant. 2009; 3: S1S155.

88. Moritz MJ, Constantinescu S, Coscia LA, Armenti D. Mycophenolate and pregnancy: Teratology principles and national transplantation pregnancy registry experience. Am J Transplant. 2017; 17: 581-582.

89. Shah S, Venkatesan RL, Gupta A, Sanghavi MK, Welge J, Johansen R, et al. Pregnancy outcomes in women with kidney transplant: Metaanalysis and systematic review. BMC Nephrol. 2019; 20: 24.

90. Combs J, Kagan A, Boelkins M, Coscia L, Moritz M, Hofmann RM. Belatacept during pregnancy in renal transplant recipients: Two case reports. Am J Transplant. 2018; 18: 2079-2082.

91. Skorpen CG, Hoeltzenbein M, Tincani A, Fischer-Betz R, Elefant E, Chambers C, et al. The EULAR points to consider for use of antirheumatic drugs before pregnancy, and during pregnancy and lactation. Ann Rheum Dis 2016; 75: 795-7810.

92. Murakami M, Ichisaka T, Maeda M, Oshiro N, Hara K, Edenhofer F, et al. mTOR is essential for growth and proliferation in early mouse embryos and embryonic stem cells. Mol Cell Biol. août 2004; 24: 6710-6718.

93. Gangloff YG, Mueller M, Dann SG, Svoboda P, Sticker M, Spetz JF, et al. Disruption of the mouse mTOR gene leads to early postimplantation lethality and prohibits embryonic stem cell development. Mol Cell Biol. 2004; 24: 9508-9516.

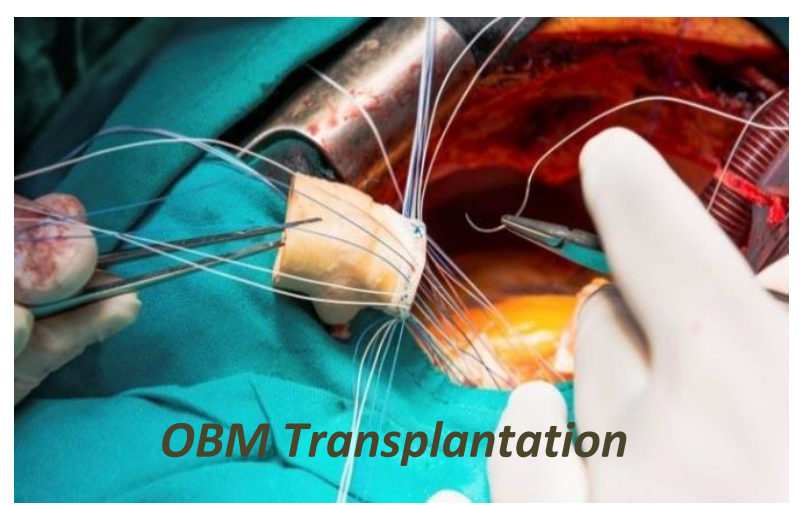

Enjoy OBM Transplantation by:

1. Submitting a manuscript

2. Joining in volunteer reviewer bank

3. Joining Editorial Board

4. Guest editing a special issue

For more details, please visit:

http://www.lidsen.com/journals/transplantation 